\title{
4 Distributing scarce adaptation finance across SIDS: effectiveness, not efficiency
}

\author{
Christian Baatz and Michel Bourban
}

\begin{abstract}
Although Small Island Developing States (SIDS) receive high amounts of adaptation finance on a per capita basis, current and expected funding is much lower than present and future adaptation costs. Since funding is insufficient to cover all needs, adaptation finance ought to benefit those who are most entitled to the funding. These entitlements can be determined via prioritisation criteria. Vulnerability is the most prominent prioritisation criterion but must be supplemented with further criteria because of its shortcomings. In this contribution we thus investigate whether cost-effectiveness and democracy should play this role. To this end, we first discuss Stadelmann and colleagues' proposal to operationalise the costeffectiveness criterion via three indicators (absolute economic savings, relative economic savings, and avoided loss of Disability Adjusted Life Years). We argue that this set of indicators fails to capture important adaptation benefits and may reinforce the current bias towards hard adaptation measures. We further claim that one should 'just' focus on safeguarding effective, that is successful, adaptation instead. To that effect, we propose 'democracy' as an alternative to costeffectiveness. We first justify the criterion by providing intrinsic and instrumental reasons in its defence and, second, discuss how to operationalise it, using the example of SIDS. We conclude that although also challenging, democracy is less difficult to operationalise than cost-effectiveness.
\end{abstract}

Cite this article: Baatz, M. \& Bourban, M. (2019): Distributing scarce adaptation finance across SIDS: effectiveness, not efficiency. In: Klöck, C. \& Fink, M. (eds.): Dealing with climate change on small islands: towards effective and sustainable adaptation? (pp. 77-99). Göttingen: Göttingen University Press. https://doi.org/10.17875/gup2019-1212 


\section{Introduction}

While Small Island Developing States (SIDS) are not a homogeneous political, social, or cultural group, they share common characteristics that distinguish them as highly vulnerable to climate change, such as smallness, isolation, and remoteness. All SIDS are exposed to severe climate impacts, such as sea-level rise, stronger and more frequent storms, coastal erosion, cyclones, and changing rainfall patterns, and thus face high relative adaptation costs (Nurse et al., 2014). For instance, the costs of shore protection works aimed at reducing the adverse effects of sealevel rise in small islands is substantially higher in terms of both per capita and percentage of GDP than the costs of similar structures in larger territories with larger populations and higher levels of gross national income per capita (Nurse et al., 2014).

Many SIDS use international adaptation financing to meet adaptation costs and ease domestic constraints. Between 2003 and 2017, multilateral climate funds provided US $\$ 1,380$ million to the 38 UN member SIDS for 210 projects of both mitigation and adaptation. Approximately 56\% of climate finance has contributed to adaptation efforts, $25 \%$ has contributed to mitigation, $3 \%$ has contributed to REDD projects, and 16\% has had multiple foci (Watson, Bird, Schalatek, \& Keil, 2017). To date, most adaptation finance has been provided through bilateral channels. Between 2010 and 2014, OECD countries self-reported committing an estimated US $\$ 2$ billion in adaptation finance to all 58 countries classified as SIDS, $51 \%$ of which went to Cabo Verde, Dominican Republic, Haiti, Guyana, and Timor-Leste (Robinson \& Dornan, 2017). On a per capita basis, SIDS were among the largest recipients of adaptation aid between 2010 and 2015 (Betzold \& Weiler, 2018 , p. 116). However, it is difficult to measure aggregate flows of international adaptation finance. Even though OECD countries claim that US\$ 10.1 billion of bilateral aid was adaptation-related in 2012, Weikmans and colleagues (2017, p. 466) conclude that only US\$2.35 billion appeared to be genuinely adaptationrelated, and that only US $\$ 1.2$ billion seemed to have targeted adaptation as a principal objective. ${ }^{1}$

Still, despite growing and substantial (self-reported) adaptation finance flows to SIDS, they cover only a small part of actual adaptation needs (Watson et al., 2017, p. 1). In such a context of scarcity, finance should benefit those who are most entitled to the funding. These people can be determined, in principle at least, via so-called prioritisation criteria.

Vulnerability is the most prominent criterion in both political and academic debates. Scholars agree that adaptation finance ought to benefit those who are

\footnotetext{
${ }^{1}$ These significant differences are mainly a result of the over-coding of adaptation-relevant projects by donor countries, a problem caused by the absence of independent quality control in the Rio marker reporting system, a lack of clarity within aid agencies about the distinction between climate change adaptation and other types of environmental projects, and the pressure on developed countries to show that they are taking action on climate adaptation (Weikman et al., 2017, pp. 467-468).
} 
most vulnerable to climate change (e.g. Ciplet, Roberts, \& Khan, 2012, p. 60) and all major United Nations Framework Convention on Climate Change (UNFCCC) agreements have restated this principle (see Klein \& Möhner, 2011, pp. 16-17). Yet, as Pickering (2012, p. 5) states, "broad agreement on this issue masks two important areas of disagreement, namely how vulnerability should be conceived and measured, and whether (and which) other principles could also inform prioritization".

While SIDS have been recognised as 'particularly vulnerable' throughout the history of climate negotiations, from the UNFCCC to the Paris Agreement (Weikmans, 2016, pp. 5-7), this category is very broad. There is no consensus on the list of countries that should be classified as 'highly vulnerable' (Weikmans, 2016, p. 7). And even among SIDS, vulnerability varies considerably both between and within countries, as a result of geographical, social, and political factors (Sjöstedt \& Povitkina, 2017). For instance, SIDS include both least developed countries like Comoros and Tuvalu and high-income countries like Singapore, Trinidad and Tobago, Barbados, and Bahamas.

Treating SIDS as a group with homogeneous entitlements therefore does not make much sense. A more refined approach is necessary and several studies have developed complex, aggregate global vulnerability indices (e.g. Barr, Fankhauser, \& Hamilton, 2010; Chen et al., 2015). However, "the rankings of countries yielded by the various indicators diverge greatly" (Mathy \& Blanchard, 2015, p. 757), "there is no agreed way of assessing [...] and comparing the vulnerability of countries" (Klein \& Möhner, 2011, p. 16) and "all attempts to allocate adaptation funding based on aggregate national-level indices of vulnerability to climate change have been deeply unsatisfying" (Füssel, Hallegatte, \& Reder, 2012, p. 323). ${ }^{2}$ This may not come as a surprise since data aggregation requires a lot of empirical and normative assumptions, some of which are rather controversial. As long as no agreed methodology exists, aggregating many heterodox factors that influence vulnerability into a single number will "not reveal more but rather disguise[s] what is known" (Hinkel, 2011, p. 205). Therefore, basing the prioritisation of adaptation finance on such an index-based vulnerability ranking is too arbitrary and not a reasonable option (Barr et al., 2010, pp. 845-846; Füssel, 2010, p. 608; Hinkel, 2011, p. 206).

If vulnerability should not be the sole, and perhaps not even the main, prioritisation criterion, distributing funding on the basis of the (expected) benefits of different adaptive measures might be a reasonable complementary criterion. In this regard, Stadelmann and colleagues (2014, 2015) propose different costeffectiveness indicators that enable such comparisons. Since we dispute that using these indicators as universal metrics in the prioritisation of adaptation finance is desirable and think that alternative indicators for cost-effectiveness would face similar problems, we propose 'democracy' as a better complementary criterion to

2 The verdict also holds for more recent studies (Baatz, 2017). 
vulnerability to check whether conditions exist that allow for desirable adaptation processes and outcomes.

All three criteria already seem to play some role in the distribution of international funding in practice. Countries that are more vulnerable to climate change tend to receive more bilateral adaptation finance, at least if the physical components of vulnerability, that is exposure and sensitivity to climate risks, are measured (Betzold \& Weiler, 2018, p. 166). Since vulnerability is also influenced by social factors determining people's adaptive capacity (IPCC, 2014, p. 21), a distribution according to physical vulnerability may not prioritise the most vulnerable, all things considered. Bilateral donors also tend to give more adaptation finance to better governed countries, since they are perceived as better able to use resources in an effective and efficient manner (Betzold \& Weiler, 2018, p. 116). Thus, (perceived) efficiency, i.e. cost-effectiveness, seems to influence funding decisions but is not used as a discrete allocation criterion. The level of democracy, on the other hand, is positively correlated with the amount of foreign aid a country receives (e.g. Dollar \& Levin, 2006). Similarly, well-governed countries are substantially more likely to receive adaptation finance and to receive higher levels of adaptation aid per capita (Weiler, Klöck, \& Dornan, 2018, p. 74). The notion of good governance and how it is measured by Weiler and colleagues, however, includes aspects that go beyond democracy (e.g. whether regulation enables growth), and the robustness of the indices usually employed to measure democracy has been questioned (e.g. Thomas, 2010). It is therefore likely that democracy positively affects funding levels.

This chapter does not investigate whether and how these criteria are used, but aims at answering the normative question of whether cost-effectiveness and democracy should guide the distribution of scarce funding in the context of adaptation. We proceed as follows: Section 2 critically discusses Stadelmann and colleagues' proposal; Section 3 briefly argues that, instead, criteria and related indicators should show to what extent conditions allowing for effective adaptation prevail; Section 4 develops our proposal for a democracy criterion; and Section 5 summarises key findings.

\section{Cost-effectiveness as a (further) prioritisation criterion?}

Generally, adaptation funding should be effective, i.e. reach its desired goal(s). In human systems, the goal of adaptation is to reduce current and expected climateinduced harms (Field et al., 2014, p. 40; Hartzell-Nichols, 2011). ${ }^{3}$ Reducing harm is a very general goal when it comes to adaptation finance. Given scarce funding, among other things, a reasonable aim of international adaptation finance is not so

\footnotetext{
3 The IPCC adds that adaptation also aims at exploiting beneficial opportunities (Field et al., 2014, p. 40). As the goal of adaptation finance should be minimising or avoiding net harm, we ignore this aspect.
} 
much to reduce - and ideally avoid - any kind of harm, but to minimise serious harm.

In order to determine which harm should count as 'serious', a normative theory is required. In line with previous works we adopt a human rights framework according to which all human beings have certain rights, as for example those laid down in the Universal Declaration of Human Rights (1948). Everybody is bound by these rights and the associated duties not to violate them, to contribute to protecting them, and to aid those deprived of their rights (Shue, 1980). On this account, all those harms are serious that undermine people's ability to exercise their human rights. ${ }^{4}$ The account offers a sufficientarian threshold of what people are entitled to as a matter of justice. People may be entitled to more in terms of global justice (i.e. what people from everywhere owe them) and to much more in terms of national justice (i.e. what they are owed by fellow citizens). As citizens of country $\mathrm{X}$ they may be entitled to basic income, education, health services, and so on that go (far) beyond what is established by this human rights account. We adopt a less demanding standard to avoid controversial but unnecessary assumptions.

There is a broad agreement in the literature that climate change will undermine and is already undermining the exercise of several internationally protected human rights, such as the right to life, to an adequate standard of health, to the means for subsistence, and to shelter and property - and this also holds for inhabitants of SIDS (Humphreys, 2010). Adaptation aims at maintaining or restoring the conditions under which people can exercise these rights in the face of climate change threats (for detail see Baatz, 2017, as well as Caney, 2012). This goal can be reached to varying degrees. If funding is insufficient to protect the human rights of all people foreseeably threatened by climate change, it seems reasonable to support those measures that best protect human rights: that is, which protect as many people as possible for a given amount of funding. Put in more general terms, those measures should be funded that are most efficient or cost-effective. Cost-effectiveness is a term prominently used in health care and denotes the measures that achieve the greatest improvement in health for a given amount of resources (World Health Organization, 2019). Here, cost-effectiveness analysis aims at identifying projects that deliver the greatest adaptation benefit, in terms of human rights protected, for a given amount of funding.

As with vulnerability, cost-effectiveness must be 'measured' or specified to guide funding decisions. To compare adaptation benefits across projects, Stadelmann and colleagues $(2014,2015)$ propose corresponding indicators. They argue that what is ultimately of interest is not the output or outcome (e.g. trained people or built dams) but the impact of a given adaptation project (Stadelmann, Persson, Ratajczak-Juszko, \& Michaelowa, 2014, p. 110). But the impacts of a project are hard to predict, especially for soft and flexible measures as well as for those

4 Alternatively, one could adopt the capabilities approach (see e.g. Schlosberg, 2012; Govind, 2013; Shockley, 2014). This does not affect our argument below that the diverse nature of adaptation benefits heavily complicates measuring and comparing the cost-effectiveness of adaption projects. 
that support basic development. Moreover, even if it were possible to predict the likely effects, accurately measuring these effects in a way that makes them comparable across projects and regions would remain a major challenge (Stadelmann et al., 2014, p. 108).

Faced with these problems, Stadelmann and colleagues (2014, p. 110) "rely on a set of three indicators that try to proxy cost-effectiveness: absolute economic savings, relative economic savings, and human lives saved per USD of spending". The absolute economic savings indicator is defined as the monetised assets saved by adaptation. Since it ignores non-monetised benefits and favours wealthy people and regions over poor ones, the authors use two additional indicators (Stadelmann et al., 2014, p. 110). Relative economic savings "are defined as the percentage of annual income saved, multiplied with the number of beneficiaries. [...] Human lives savings are measured in Disability Adjusted Life Years Saved (DALYs) [sic], an indicator systematically utilized by the World Health Organization" (Stadelmann et al., 2014, p. 111). The authors aim at avoiding a "monetary-only approach" while at the same time allowing for universal comparisons of projects, i.e. across different areas, that are not possible so far because existing approaches only work within areas or sectors (Stadelmann, Michaelowa, Butzengeiger-Geyer, \& Köhler, 2015, p. 2149).

\subsection{Absolute economic savings}

Despite the shortcomings of absolute economic savings measured via saved monetised assets, the authors supplement rather than replace the indicator because "it is the usual way to measure macro-economic effectiveness, it is a standard indicator for evaluating the well-being of societies, it reflects overall utility as stated by market participants" (Stadelmann et al., 2014, p. 111). The fact that something is routinely used is not a justification for using it as well and it has been doubted for quite some time that absolute economic savings or even economic savings is a good indicator of the wellbeing of societies or, rather, people (e.g. Sen, 1999).

In the context of adaptation, the indicator is likewise problematic. The key objective of adaptation is to avoid serious harms caused by climatic changes; it protects what is of value against loss and damages and fulfils this function for people in very different situations. Where more valuable objects and opportunities exist, more can be lost. Therefore, more losses can be prevented by undertaking adaptation where many objects and opportunities exist. If all of these objects and opportunities were of equal worth, it would make sense to favour measures that protect more of them, as argued above. However, absolute economic savings hardly measure equally valuable things. According to this indicator, a loss of US\$100 for a member of the Singaporean elite and a subsistence farmer in the Comoros has the same weight (Stadelmann et al., 2014, p. 111). Moreover, while many fundamental losses are hardly captured by the measure (say, a person contracts dengue fever, does not receive medical treatment, and dies), comparatively trivial monetary losses 
of affluent persons are fully accounted because they are reliably captured by this indicator. ${ }^{5}$

\subsection{Relative economic savings and DALYs}

There are different ways to adjust the economic savings indicator in order to dampen the bias in favour of wealthier people. The option suggested by Stadelmann and colleagues is measuring the percentage of annual income saved. The main drawback of the relative economic savings indicator (as percentage of annual income saved) is that it ignores all effects that are not income related. And while the protection of income is often very important, the adaptation literature stresses that vulnerability to climate change cannot be reduced to lack in income (Paavola \& Adger, 2006, p. 605). Furthermore, the criterion ignores how the person that loses (part of) her income is situated, that is, how wealthy/poor she is (see also Persson \& Remling, 2014, p. 29). This is relevant for losing, say, $10 \%$ of one's income might impose serious hardship on a poor person while it does not for a very wealthy member of society. Overall, the criterion is under- and over-inclusive: it does not capture human rights threats that are not related to income losses and captures income losses that are not related to human rights threats. An indicator that does not adequately capture whether adaptation is effective faces problems when comparing the cost-effectiveness of various projects.

The under-inclusiveness of relative economic savings is reduced by adding the third indicator, DALYs lost, which is more directly related to human rights threats. A reduction in DALYs may indicate that the right to life and to an adequate standard of health care are temporarily or permanently undermined. ${ }^{6}$ In combination, DALYs and relative economic savings might better indicate threats to human rights. The remaining problem is that both indicators do not capture many effects that are highly relevant.

We illustrate this point by drawing on the distinction between so-called hard and soft adaptation measures, referring to technology-driven infrastructure projects like dams or irrigation systems and to changes in planning, institutional settings, and behaviour respectively (Fankhauser \& Burton, 2011, p. 1045). While "there is a well-known and long-observed practice in adaptation studies to prefer hard [...] over soft measures" (Fankhauser \& Burton, 2011, p. 1045), the latter are at least as important as the former. Usually, non-climatic factors make people vulnerable to climate change: the "lack of social, political, and economic resources that poor and marginal communities fail to command is the main factor creating

\footnotetext{
${ }^{5}$ It is noteworthy that, strictly speaking, human rights do not measure things of equal moral worth either, for one would probably say, for example, that the right to life is of greater importance than the right to establish unions. However, the problem of giving equal weight to unequal values is much graver in the case of economic savings.

${ }^{6}$ However, mild diseases will increase the number of DALYs but will not undermine the exercise of human rights.
} 
their inability to cope with climatic changes" (Khan \& Roberts, 2013, p. 183). Activities that effectively reduce vulnerability (also) need to tackle these factors, and technology-based measures that address specific climate impacts are unable to do so (Roberts \& Parks, 2007, p. 132; Klein \& Persson, 2008, p. 40; Ayers \& Dodman, 2010, p. 165). Effective adaptation often can be achieved by changes in practices, and when hard adaptation is effective it needs to be accompanied by design or regulatory, i.e. soft, measures (e.g. Fankhauser \& Burton, 2011, p. 1045).

Therefore, it is crucial to overcome the bias towards hard measures, but the indicators proposed by Stadelmann and colleagues may rather reinforce it. Consider two examples: Protecting flood-prone shores of SIDS from inundation might allow for a straightforward calculation of losses prevented in the future. In comparison, a successful development policy, a reform of the schooling system, or a change in regulations may result in very beneficial developments in the long-run that are, at the same time, difficult to predict and to accurately calculate. It would be challenging, for example, to express the benefits of the schooling reform in terms of the avoided loss in DALYs or income. Using these indicators may thus favour hard over soft measures.

The shortcomings of these cost-effectiveness indicators can also be illustrated by the serious non-economic losses inhabitants of SIDS are facing. Sea-level rise may force many people to leave their home, even their country. To the extent that people will be dispersed through various places willing to accept immigrants in a limited number, they face the threat of cultural and linguistic loss that can undermine the social bases of self-respect (Zellentin, 2015, pp. 496-497; see also Farbotko, this volume). These as well as other non-economic losses and damages associated with 'climate migration' are not captured by the indicators.

Stadelmann and colleagues highlight the major challenge of measuring adaptation benefits in a way that makes them comparable across projects and regions. For the reasons just stated, we do not think that the indicators they propose even come close to meeting the challenge because too many important effects are not captured by them. However, we acknowledge that any indicator will face this problem because the benefits of adaptation are highly diverse and cannot be captured with one or two indicators (see examples of economic, social, and environmental benefits provided in Remling \& Persson, 2015, p. 27). We thus doubt that it makes sense to universally compare the cost-effectiveness of adaptation projects as this would require a host of different indicators that are based on incommensurable values as well as the quantification of effects that are both hard to predict and hard to measure. ${ }^{7}$ But note that our argument leaves the door open to use relative economic savings and avoided DALYs losses ${ }^{8}$ for projects whose key aim is to protect

\footnotetext{
${ }^{7}$ Scepticism regarding the usefulness of a cost-effectiveness criterion is also voiced by Paavola and Adger (2006, p. 605) and Persson et al. (2009, p. 89).

${ }^{8}$ In the context of public health and medical ethics, the DALYs approach faces severe criticism on both methodological and normative grounds (e.g. Daniels, 2008; Klonschinski, 2016). We deal with this critique in future work on the (non-)relevance of efficiency considerations in adaptation finance.
} 
people's income and health respectively. In this vein, it might make sense to compare similar projects across regions/countries or different types of projects with the same aim in one region/country.

\section{Focusing on conditions for effective adaptation}

Given the difficulties of determining cost-effective measures in a reasonable way, we suggest using alternative criteria that focus on the more basic challenge: ensuring that adaptation is effective at all. Due to the well-known barriers to adaptation, ${ }^{9}$ achieving effectiveness is far from trivial. Effectiveness is determined not only by case-specific factors, such as project idea and design, but also by the capacity of regional or national authorities to implement effective adaptation projects (Persson \& Remling, 2014, p. 494). For this reason, implementation capacity could serve as a general criterion to prioritise funding. But higher implementation capacity usually means better governance and higher adaptive capacity (Pickering, 2012, p. 5). Since adaptive capacity is a component of vulnerability, higher adaptation and implementation capacity means lower vulnerability.

Faced with the trade-off between effectiveness (specified via implementation capacity) and vulnerability, Barr and colleagues (2010, p. 852) argue that low implementation capacity should not be a reason to provide less funding to a country: "Insufficient implementation capacity may point to [...] stricter monitoring arrangements and a stronger role for development agencies in project management. It also points to a need for capacity building as an adaptation (and development) priority". And "a more hands-on approach on project implementation may be required" in these cases (Barr et al., 2010, p. 854). Pickering (2012, p. 845) correctly stresses that "even 'hands-on' approaches may be insufficient to counter major obstacles to implementation such as civil conflict or entrenched corruption".

These considerations highlight that the reasons for low implementation capacities matter for funding decisions. If a country 'merely' lacks the bureaucratic apparatus, the know-how to develop effective adaptation measures, and/or the capacity to absorb, manage, and distribute substantial amounts of international funding, capacity building indeed is the correct way forward. If, on the other hand, the main problem consists in, say, kleptocratic forms of government, supporting the enlargement of the bureaucratic apparatus will most likely increase corruption levels and hardly benefit marginalised and vulnerable groups.

Therefore, universal criteria should indicate whether the conditions that allow for effective adaptation are present or can be facilitated via the funding. The next section proposes 'democracy' as one possible criterion to fulfil this function. We suggest that capacity building is more reasonable in democratic than in non-

\footnotetext{
${ }^{9}$ Barriers to effective adaptation in SIDS include for instance access to financial, technological, and human resources, issues related to cultural and social acceptability of measures, and constraints imposed by the existing political and legal frameworks (Nurse et al., 2014).
} 
democratic countries. Non-democratic countries would instead require something like 'democracy building'. ${ }^{10}$ Next, we therefore defend the idea that prioritising democratically governed people is justified.

\section{Towards a democracy criterion}

By 'democracy', we refer 'to a method of group decision making characterized by a kind of equality among the participants at an essential stage of the collective decision making" (Christiano, 2015). The degree of equality can be more or less deep: It can represent mere formal equality, such as the one-person one-vote rule in an election, or a more robust form of equality, such as equality in the process of deliberation. It may involve either direct participation of members of society in law and policy making or selection of representatives (Christiano, 2015). Democracy does not require perfect equality, but a certain degree of equality: regarding opportunities for political participation, individual freedoms, limited influence of private interests over the state, and so on.

\subsection{Reasons for a democracy criterion}

In this sub-section, we offer (what may be called) intrinsic and instrumental reasons in favour of a democracy criterion, starting with the former.

From the perspective of climate ethics, people in the Global South vulnerable to climate change are entitled to support from the Global North in their adaptation efforts (for detail see Baatz, 2013, 2017). Adaptation finance is owed to the persons whose rights are threatened or undermined and, once provided, it is owned by these people (Duus-Otterström, 2016). The human rights perspective entails that it is not owned by the representatives of a citizenry or the country as a collective.

However, it does not make much sense to pay adaptation finance to individuals. Adaptation that effectively protects people usually must be undertaken at the collective level. And since the benefits of various adaptive measures are difficult to estimate (see above), it must be decided at the collective level where to undertake which projects. Thus, adaptation usually involves a considerable amount of collective decision-making. But due to citizens' entitlement to the funding, they ought to participate in the collective decision-making process, ideally with an equal say. This does not necessarily mean that everyone whose human rights are threatened ought to have the opportunity to personally participate in the decision-making on how to spend adaptation finance, but that their interests must be appropriately represented. According to the human rights account we endorse, people threatened by climate change are not seen as helpless and speechless victims but rather as bearers

${ }^{10}$ We discuss in a separate paper under development whether adaption finance should also be used in this regard (Bourban \& Baatz, 2019). 
of the right to voice their interests and concerns as equals in policy discourses. If this is not possible, opportunities for political participation ought to be created.

In addition to this entitlement argument, the presence of democratic institutions is also likely to increase the effectiveness of adaptation finance. The following presents two such instrumental reasons in favour of the democracy criterion.

First, the incorporation of local knowledge in the planning of adaptation increases its effectiveness. While vulnerable people will often benefit from financial, technical, and informational support, their knowledge and awareness are important for effective adaptation (Khan \& Roberts, 2013, p. 183; Biagini, Bierbaum, Stults, Dobardzic, \& McNeeley, 2014, p. 105; Heyward, 2017, p. 482). The Intergovernmental Panel on Climate Change (IPCC) even observes that support by local actors and community engagement constitute a prerequisite for successful adaptation (Mimura et al., 2014, p. 881). Otherwise, there is the risk that activities are funded "which suit the interests of more powerful stakeholders, but struggle to bring benefits to the most vulnerable communities" (Fenton, Gallagher, Wright, Huq, \& Nyandiga, 2014, p. 391; similarly Duus-Otterström, 2016, p. 665). There is a consensus in the literature that local adaptation governance should be democratised in order to prioritise the predicament of the poor and the marginalised (Mikulewicz, 2018, p. 26). Therefore, robust democratic decision-making increases the likelihood that local citizens affected by adaptation can incorporate their knowledge, ideas, and concerns into the decision-making process on how to adapt.

Second, democratic institutions and procedures make corruption and misuse of funding more difficult and these phenomena in turn undermine effective adaptation. As Paavola and Adger (2006, p. 606) put it: "Where democratic structures are absent, planning for climate change is little more than a rhetoric within a landscape of unsustainable development".

According to Transparency International (2011, xxvi), the extent to which policy development and decisions are participatory, accountable, transparent, and respect the rule of law will determine how serious corruption risks are. The risk is lower if democratic institutions ensure working checks and balances between branches of the government and include effective non-governmental watchdogs, from the media to civil society organisations and independent academic institutions (Vogl, 2012, p. 153). Disclosure of information and participation in decisionmaking are especially crucial (Horstmann, 2011, p. 249), since they enable the general public and entitlement-bearers to retrace inappropriate capture of resources.

While the relationship between democracy and corruption is complex, recent empirical studies generally support the claim that democracy reduces corruption (Kolstad \& Wiig, 2016) but also highlight that mere formal equality in the form of 'one person one vote' in regular elections is not enough: media freedom (Bhattacharyya \& Hodler, 2015), income to meet basic needs (Neudorfer, 2015; Jetter, Agudela, \& Hassan, 2015), limited economic inequality (You, 2016), availability of information (Boehm, 2015), and well-functioning checks and balances (Boehm, 2015; Saha, Gounder, Campbell, \& Su, 2014) are additional conditions for 
democracy to curb corruption. Regarding the definition of democracy as equality in collective decision-making mentioned above, these results suggest that the degree of equality must be sufficiently high: that is, it requires that most citizens can make use of certain rights and have access to information, that material inequality is limited, and so on. Thus, the higher the degree of equal opportunities for political participation, the less likely is corruption and misappropriation of public funding.

So far, our argument has linked non-democratic decision-making with corruption. We further assume that corruption hampers effective adaptation because part of the money is not used for adaptation at all and because it supports corrupted practices, possibly leading to a vicious cycle increasing both corruption and vulnerability (Transparency International, 2018, p. 2). In addition, corruption might also distort public decision-making towards the interests of those with the ability to bribe - and we assume that these persons are usually not those whose human rights are most threatened. We are not aware of empirical studies on the relationship between corruption and adaptation effectiveness. However, in this respect adaptation finance is very similar to development aid and the literature on corruption and aid effectiveness indicates a negative correlation: While some studies suggest that corruption increases desirable outcomes in certain settings, e.g. by alleviating the distortions caused by ill-functioning institutions (Méon \& Weill, 2010), the bulk of recent contributions arrive at the opposite conclusion (e.g. Winters, 2010; Lee, Yang, \& Kang, 2016; Smillie, 2017). To what extent these results accurately describe the corruption-effectiveness relationship and apply to the adaptation context remains to be seen (and investigated), but we consider this to be plausible.

In sum, we have argued that democracy makes corruption and bad policy making less likely (we have not argued that it safeguards against such problems). Also note that even if non-democratic governments allow for effective adaptation, the intrinsic argument that stresses the non-instrumental value of political participation remains valid. Citizens are to be recognised as equally worthy moral agents who must be allowed to speak for themselves. The misrecognition of its citizens is an injustice which undermines a government's role as a legitimate trustee of adaptation finance. For these reasons, the extent of democratic decision-making should be considered in the prioritisation of adaptation finance.

\subsection{Specifying and 'measuring' democracy in SIDS}

Just like vulnerability and cost-effectiveness, democracy is a complex concept. To be of use in the distribution of adaptation finance, the degree of democratic decision making somehow needs to be 'measured'. And here one may expect problems very similar to those of measuring vulnerability and cost-effectiveness. This subsection offers a first, tentative discussion of one way to operationalise the criterion 
via the Varieties of Democracy (V-Dem) Indicators, a rather new approach to conceptualising and measuring democracy.

In the 2018 V-Dem report, the authors develop what they describe as the largest democracy database, with 450 indicators and indices of democracy covering 201 countries from 1789 to 2017 by relying on the expertise of over 3,000 scholars and country experts (Lührmann, 2018a; Lührmann, 2018b). They define democracy according to five core elements, each of them being measured by a different index: the electoral principle, the liberal principle, the egalitarian principle, the participatory principle, and the deliberative principle.

Following our definition of democracy and our justification of this criterion in the adaptation context, we focus here on the egalitarian and the participatory principles. Without some participation in decision-making and basic equality among citizens, citizens cannot voice their interests and concerns as equals in policy discourses (intrinsic reason) and cannot incorporate their ideas and values in the planning process (first instrumental reason). The lack of both aspects also makes corruption more likely, which will hinder planning and implementation of projects and programmes that protect those whose human rights are (most) at risk (second instrumental reason). Participation and basic equality might prevail even if national, regional, or local modes of decision-making in SIDS differ from those in Western liberal democracies. Thus, by focusing on the egalitarian and the participatory principle, the indicators are correlated with the key ideas behind the criterion.

The V-Dem Egalitarian Component Index measures to what extent social groups enjoy political participation according to their ability to make informed voting decisions, to express their opinions, to demonstrate, to run for office, and to influence policymaking. It is particularly interested in the degree of equality of protection of individual rights and freedoms from the state as well as the degree of equality in the distribution of resources to ensure that individuals can have access to the basic necessities enabling them to exercise their rights and freedoms (Sigman \& Lindberg, 2015, p. 1). Each component of the index strives to capture these two theoretical dimensions of the egalitarian principle. Indicators used in the Equal Protection subcomponent include equal access to justice, social class equality in respect for civil liberties, and social group equality in respect for civil liberties (Sigman \& Lindberg, 2015, p. 10). These measures reflect the extent to which rights and freedoms are applied equally across the population of a given country. Indicators used in the Equal Distribution of Resources subcomponent include educational equality, health equality, and the power distribution according to social groups and gender (Sigman \& Lindberg, 2015, p. 11).

A challenge is potential trade-offs between components within the egalitarian index. As Coppedge and colleagues (2018, p. 14) explain, contradictions between and within principles are unavoidable because of democracy's multi-dimensional character. However, strong correlations among the indicators show that there are good grounds for the robustness of the egalitarian index. High degrees of equal distribution of resources and high levels of equality in participation are mutually 
reinforcing dynamics, which suggests that the index does measure accurately the egalitarian principle and avoids insurmountable contradictions between its indicators (Sigman \& Lindberg, 2015, pp. 14-17).

The V-Dem Participatory Component Index measures active participation by citizens in political processes by focusing on civil society organisations, mechanisms of direct democracy and participation, as well as representation through local and regional governments. The index relies on three arenas of participation: the electoral arena, political parties, and civil society. Each arena is measured by indicators from three dimensions: the institutional context, which refers to the procedures and structures allowing citizens to have opportunities to participate in elections, political parties, or civil society organisations; the organisational context, which asks whether citizens embrace these opportunities; and the cultural dimension, which asks how citizens make use of participation. For instance, indicators measure the degree to which elections are free, fair, and multi-party (first arena), the existence of bans on political parties and the autonomy of opposition parties (second arena), and the freedom to join and exit civil society organisations, the extent to which civil society is repressed, and its role in public policy consultation (third arena). Here again, although the degrees of correlation vary, there are strong correlations among indicators, especially between participation in political parties and in civil society (Fernandes, Cancela, Coppedge, Lindberg, \& Hicken, 2015, pp. 21-25).

Despite these strong correlations that contribute to the robustness of the egalitarian and the participatory indices, one should keep in mind that the set of indicators used by V-Dem is not exhaustive. It is comprehensive, but the complex nature of equality and participation resists closure (Coppedge et al., 2018, p. 14).

Having introduced the V-Dem project and two of its indices, we next offer exemplary results on the level of political equality and participation in selected SIDS, briefly discuss how decision-makers can use this information, and comment on limited data availability in the case of SIDS.

Political diversity among SIDS is well illustrated by different levels of democracy. The V-Dem ranking is based on a scale from 0 (very undemocratic) to 1 (very democratic) and there is no threshold for a country to be considered as democratic or undemocratic. For 2017, SIDS that ranked the highest in the egalitarian index were Mauritius (0.67), Cape Verde (0.65), Barbados (0.63), Trinidad and Tobago (0.63), and Suriname (0.62), while SIDS that ranked the lowest were Cuba (0.25), Dominican Republic (0.24), Maldives (0.22), and Papua New Guinea (0.22). Regarding the participatory index, SIDS that ranked the highest were Jamaica (0.56), Suriname (0.53), Mauritius (0.51), and Cape Verde (0.48), while those that ranked the lowest were Maldives (0.2), Fiji (0.17), Singapore (0.14), Cuba (0.07), and Bahrain $(0.04) .^{11}$

11 We used the "Variable graph" to generate and compare these data: https://www.vdem.net/en/analysis/VariableGraph/. 
Equality and participation correlate strongly, indicating that these two essential components of democracy tend to be mutually reinforcing. Countries that score high in the egalitarian index, such as Mauritius, Cape Verde, and Suriname, also score the highest in the participatory index. Likewise, countries that score low in the egalitarian index also tend to score low in the participatory index, as the cases of Maldives and Cuba illustrate. Since the levels of equality and participation have risen since the 1950s in Mauritius, Cape Verde, and Suriname and have kept relatively constant since the 2000s (between 0.62 and 0.72 for the egalitarian index and between 0.48 and 0.56 for the participatory index, if we take into account all three countries), the V-Dem indices also show that there is a certain form of stability in relatively high levels of equality and participation in these countries that cannot be found in countries that are less democratic, such as Maldives and Cuba.

Instead of going into further detail regarding these data, we comment on how to make use of the information provided by the indices in the context of adaptation finance. On the one hand, with V-Dem a sophisticated and robust tool to measure democracy in recipient countries is available. On the other hand, contradictions between and within V-Dem indices remain possible and some arbitrariness in the choice of indicators cannot be fully avoided. For this reason, and not surprisingly, the indices should not be turned into or become part of a distributive formula. But we do think that this information should be considered in decisions regarding the distribution of funding.

Basically, the democracy criterion can play two distinct roles in the context of adaptation finance: it can affect either the modality or the amount of funding provided. In the case of the former, the conditionalities attached to the funding should increase with a decreasing level of democracy. The fewer opportunities for political participation there are, the higher the need to specify and to monitor how funding is used. In the case of latter, funding is reduced as levels of democracy are lower or even withheld in the case of very undemocratic countries. This might be justifiable by reference to highly insufficient available funding and in cases where confidence is low that imposed conditionalities can safeguard effective adaptation. However, poor governance is a driver of vulnerability and many people that are particularly vulnerable to climate change are governed in non-democratic countries. Withdrawal of funding would mean that these people would not benefit from adaptation finance. There are no easy answers on how to deal with this trade-off, unfortunately, and we further investigate the matter in a separate research paper under development (Bourban \& Baatz, 2019). How this question is answered also affects whether level of democracy should influence the modality or the amount of funding provided, or both. Therefore, we remain agnostic here regarding which of the two roles the democracy criterion should play.

One problem that V-Dem shares with many other indices is low availability of data. Since comprehensive data are required for measuring its components, and despite its broad coverage of more than 200 countries, many SIDS are not yet covered by V-Dem (see Table 1). This research gap should be closed as soon as 
possible to make full use of the democracy criterion and V-Dem respectively. As long as the gap persists, it may be possible to draw on other indicators that have data for these countries, such as the Worldwide Governance Indicators (WGI), especially the "Voice and Accountability" and "Control of Corruption" indices (World Bank, 2018), that cover almost all SIDS. This can make sense if these indicators exhibit strong correlations with V-Dem indices in countries covered by both. Also, if funding agencies have reliable information on the extent of democratic processes, they can use that information, for instance, to tie funding to additional conditionalities or provide more funding to another region/country. When only inconclusive data is available, the democracy criterion needs to be ignored. Whether and how to fund what kinds of adaptation projects in a given region, is then based on all other relevant considerations. For a multi-criteria, non-formulaic approach used by all bi- and multilateral funding agencies, such data gaps are not a fundamental drawback to our argument that considering democracy levels is desirable and in many cases possible.

Table 1: V-Dem's Coverage of SIDS: UN member SIDS are marked with an asterisk; SIDS eligible to receive official development assistance (ODA) are highlighted in italics (UNFCCC, 2018).

\begin{tabular}{|c|c|}
\hline $\begin{array}{l}\text { Currently cov- } \\
\text { ered by V-Dem }\end{array}$ & $\begin{array}{l}\text { Bahrain*, Barbados*, Cape Verde*, Comoros*, Cuba*, Domini- } \\
\text { can Republic*, Fiji*, Guinea Bissau*, Guyana*, Haitı*, Jamaica*, } \\
\text { Maldives*, Mauritius*, Papua New Guinea*, São Tomé and } \\
\text { Principe*, Seychelles*, Singapore*, Solomon Islands*, Suriname*, } \\
\text { Timor-Leste*, Trinidad and Tobago*, Vanuatu* }\end{array}$ \\
\hline $\begin{array}{l}\text { Currently not } \\
\text { covered by V- } \\
\text { Dem }\end{array}$ & $\begin{array}{l}\text { American Samoa, Anguilla, Antigua and Barbuda*, Aruba, } \\
\text { Bahamas*, Belize*, British Virgin Islands, Cook Islands, } \\
\text { Dominica*, Federated States of Micronesia*, French Polynesia, } \\
\text { Guam, Grenada*, Kiribati*, Marshall Islands*, Montserrat, } \\
\text { Nauru*, Netherlands Antilles, New Caledonia, Niue, } \\
\text { Northern Mariana Islands, Palau*, Puerto Rico, Samo*, } \\
\text { Saint Kitts and Nevis*, Saint Lucia*, Saint Vincent and the } \\
\text { Grenadines*, Tonga*, Twvalu*, United States Virgin Islands }\end{array}$ \\
\hline
\end{tabular}

Finally note that operationalising democracy as understood here is less difficult than operationalising cost-effectiveness (and possibly even vulnerability). We argued that adaptation benefits are diverse and that avoided DALYs losses and relative income only capture certain types of benefits. Perhaps a comprehensive approach of measuring cost-effectiveness comparable to the V-Dem project might remedy this shortfall. However, a universal cost-effectiveness criterion entails comparisons of things that are difficult to compare (improvements in, say, education, health, and ecosystems) and must rely on predictions of the (long-term) ef- 
fects of adaptation measures, which are usually marked by substantial uncertainty. In contrast, the democracy criterion requires no such predictions for it checks whether desirable conditions predominate at present. Moreover, while we acknowledge that participation and equality are not easy to 'measure', these notions are less heterogeneous than the concept of adaptation benefits. That is to say, a comprehensive operationalisation of cost-effectiveness would require collecting and aggregating more, and more diverse data than required for the egalitarian and the participatory indices. Thus, although many questions on how to operationalise the democracy criterion are yet to be settled, the task seems less daunting than operationalising the cost-effectiveness criterion and possibly even the vulnerability criterion.

\section{Conclusion}

International funding to support adaptation projects in SIDS is scarce. To determine who is most entitled to adaptation projects, prioritisation criteria are needed. The most prominent criterion, vulnerability, faces drawbacks and should be complemented by further criteria. Cost-effectiveness could be such a criterion but so far indicators proposed to operationalise it are not suitable and/or are insufficient. Absolute or relative economic savings and avoided losses of DALYs do not capture important adaptation benefits and may reinforce the problematic bias towards hard adaptation measures. Rather than comparing adaptation benefits across projects, universal criteria and associated indicators should show whether the conditions that allow for effective adaptation are present or can be facilitated via funding. The criterion of democracy highly fulfils this function because equal opportunities for participating in collective decision-making increase the likelihood that local knowledge is incorporated into adaptation decisions and reduce the likelihood of corruption and misuse of funding. Moreover, such opportunities enable those entitled to adaptation projects to participate in making decisions about how to adapt, which is intrinsically valuable. In terms of the operationalisation of the criterion, the V-Dem indicators - especially the egalitarian and the participatory indices - seem to present a viable path, although whether and to what extent this claim holds requires more detailed investigation. We want to start rather than close this debate.

\section{Acknowledgments}

We would like to thank Michael Fink, Carola Klöck, Andrea Klonschinski, and two anonymous reviewers for their many valuable suggestions on how to improve this paper. We also gratefully acknowledge financial support provided by the Cluster of Excellence 80 "The Future Ocean" (Project CP1771). The Future Ocean is funded 
within the framework of the Excellence Initiative by the Deutsche Forschungsgemeinschaft (DFG) on behalf of the German federal and state governments.

\section{Bibliography}

Ayers, J., \& Dodman, D. (2010). Climate change adaptation and development I: the state of the debate. Progress in Development Studies, 10(2), 161-168.

Baatz, C. (2013). Responsibility for the past? Some thoughts on compensating those vulnerable to climate change in developing countries. Ethics, Policy \& Environment, 16(1), 94-110.

Baatz, C. (2017). Compensating victims of climate change in developing countries: Justification and realization (Doctoral dissertation, University of Greifswald).

Barr, R., Fankhauser, S., \& Hamilton, K. (2010). Adaptation investments: A resource allocation framework. Mitigation and Adaptation Strategies for Global Change, 15(8), 843-858.

Betzold, C., \& Weiler, F. (2018). Development aid and adaptation to climate change in developing countries. Cham: Palgrave Macmillan.

Bhattacharyya, S., \& Hodler, R. (2015). Media freedom and democracy in the fight against corruption. European Journal of Political Economy, 39, 13-24.

Biagini, B., Bierbaum, R., Stults, M., Dobardzic, S., \& McNeeley, S. M. (2014). A typology of adaptation actions: A global look at climate adaptation actions financed through the Global Environment Facility. Global Environmental Change, 25, 97-108.

Boehm, F. (2015). Democracy and corruption. Dimensión Empresarial, 13(2), 75-85.

Bourban, M., \& Baatz, C. (2019). Vulnerability, corruption, and democratization in SIDS: Ignoring vulnerable people or unjust political structures when distributing adaptation finance? Unpublished working paper.

Caney, S. (2012). Just emissions. Philosophy \& Public Affairs, 40(4), 255-300.

Chen, C., Noble, I., Hellmann, J., Coffee, J., Murillo, M., \& Chawla, N. (2015). University of Notre Dame Global Adaptation Index: Country index technical report. Retrieved from http://index.nd-gain.org:8080/documents/nd-gain_technical_ document_2015.pdf.

Christiano, T. (2015). Democracy. In Edward N. Zalta (Ed.), The Stanford encyclopedia of philosophy (2015 ed.).

Ciplet, D., Roberts, J. T., \& Khan, M. (2012). The politics of international climate adaptation funding: Justice and divisions in the greenhouse. Global Environmental Politics, 13(1), 49-68.

Coppedge, M., Gerring, J., Knutsen, C. H., Lindberg, S. I., Skaaning, S.-E., Teorell, J. ... Wilson, S. (2018). V-Dem Methodology v8. Retrieved from https://www.v-dem.net/media/filer_public/5a/f1/5af198e9-f3e8-4619-

b9fd-a8387fdc22a5/v-dem_methodology_v8.pdf. 
Daniels, N. (2008). Just health. Meeting health needs fairly. Cambridge, UK: Cambridge University Press.

Dollar, D., \& Levin, V. (2006). The increasing selectivity of foreign aid, 1984 2003. World Development, 34(12), 2034-2046.

Duus-Otterström, G. (2016). Allocating climate adaptation finance: Examining three ethical arguments for recipient control. International Environmental Agreements: Politics, Law and Economics, 16(5), 655-670.

Fankhauser, S., \& Burton, I. (2011). Spending adaptation money wisely. Climate Policy, 11(3), 1037-1049.

Fenton, A., Gallagher, D., Wright, H., Huq, S., \& Nyandiga, C. (2014). Up-scaling finance for community-based adaptation. Climate and Development, 6(4), 388397.

Fernandes, T., Cancela J., Coppedge M., Lindberg, S. I., \& Hicken A. (2015). Measuring political participation in Southern Europe: The varieties of democracy approach. Retrieved from https://www.v-dem.net/media/filer_public/ec/eb/eceba243d87c-41dc-a9ed-6bd5d6a6ccf8/v-dem_working_paper_2015_15.pdf.

Field, C. B., Barros, V. R., Mach, K. J., Mastrandrea, M. D., Aalst, M. van, Adger, W. N., ... Yohe, G. W. (2014). Technical summary. In C. B. Field, V. R. Barros, D. J. Dokken, K. J. Mach, M. D. Mastrandrea, T. E. Bilir,. . . L. L. White (Eds.), Climate Change 2014: Impacts, adaptation, and vulnerability. Part A: Global and sectoral aspects. Contribution of Working Group II to the Fifth Assessment Report of the Intergovernmental Panel on Climate Change (pp. 35-94). Cambridge and New York: Cambridge University Press.

Füssel, H.-M. (2010). How inequitable is the global distribution of responsibility, capability, and vulnerability to climate change: A comprehensive indicatorbased assessment. Global Environmental Change, 20(4), 597-611.

Füssel, H.-M., Hallegatte, S., \& Reder, M. (2012). International adaptation funding. In O. Edenhofer (Ed.), Climate change, justice and sustainability: Linking climate and development policy (pp. 311-330). Dordrecht etc.: Springer.

Govind, P. (2013). A reorientation of climate justice: Capability justice and climate change. In F. de Londras \& S. Mullally (Eds.), Irish yearbook of international law, Volume 6, 2011 (pp. 9-23). Oxford: Hart Publishing Limited.

Hartzell-Nichols, L. (2011). Responsibility for meeting the costs of adaptation. WIREs Climate Change, 2(5), 687-700.

Heyward, C. (2017). Ethics and climate change adaptation. In A. Thompson \& S. M. Gardiner (Eds.), The Oxford handbook of environmental ethics (pp. 474-486). Oxford: Oxford University Press.

Hinkel, J. (2011). Indicators of vulnerability and adaptive capacity: Towards a clarification of the science-policy interface. Global Environmental Change, 21(1), 198-208.

Horstmann, B. (2011). Promoting an effective and transparent use of funds through the Adaptation Fund. In Transparency International (Ed.), Global cor- 
ruption report: Climate change (pp. 246-254). London and Washington, DC: Earthscan.

Humphreys, S. (Ed.). (2010). Human rights and climate change. Cambridge, UK: Cambridge University Press.

IPCC. (2014). Summary for policymakers. In C. B. Field, V. R. Barros, D. J. Dokken, K. J. Mach, M. D. Mastrandrea, T. E. Bilir,. . L. L. White (Eds.), Climate Change 2014: Impacts, adaptation, and vulnerability. Part A: Global and sectoral aspects. Contribution of Working Group II to the Fifth Assessment Report of the Intergovernmental Panel on Climate Change (pp. 1-32). Cambridge and New York: Cambridge University Press.

Jetter, M., Agudela, A. M., \& Hassan, A. R. (2015). The effects of democracy on corruption: Income is key. World Development, 74, 286-304.

Khan, M. R., \& Roberts, J. T. (2013). Adaptation and international climate policy. WIREs Climate Change, 4(3), 171-189.

Klein, R. J. T., \& Persson, A. (2008). Financing adaptation to climate change: Issues and priorities. Retrieved from http://www.ceps.eu/node/1569.

Klein, R. J., \& Möhner, A. (2011). The political dimension of vulnerability: Implications for the Green Climate Fund. IDS Bulletin, 42(3), 15-22.

Klonschinski, A. (2016). The economics of resource allocation in bealth care. Cost-utility, social value, and fairness. New York: Routledge.

Kolstad, I., \& Wiig, A. (2016). Does democracy reduce corruption? Democratization, 23(7), 1198-1215.

Lee, H. Y., Yang, B. M., \& Kang, M. (2016). Control of corruption, democratic accountability, and effectiveness of HIV/AIDS official development assistance. Global Health Actions. 9(1), 1-10.

Lührmann, A. (2018a). Democracy for All? V-Dem Annual Report 2018. Gothenburg. Retrieved from University of Gothenburg website, https://www.vdem.net/media/filer_public/3f/19/3f19efc9-e25f-4356-b159b5c0ec894115/v-dem_democracy_report_2018.pdf.

Lührmann, A. (2018b). State of the world 2017: Autocratization and exclusion? Democratization, 25(8), 1321-1340.

Mathy, S., \& Blanchard, O. (2015). Proposal for a poverty-adaptation-mitigation window within the Green Climate Fund. Climate Policy, 16(6), 752-767.

Méon, P.-G., \& Weill, L. (2010). Is corruption an efficient grease? World Development, 38(3), 244-259.

Mikulewicz, M. (2018). Politicizing vulnerability and adaptation: On the need to democratize local responses to climate impacts in developing countries. Climate and Development, 10(1), 18-34.

Mimura, N., Pulwarty, R. S., Duc, D. M., Elshinnawy, I., Redsteer, M. H., Huang, H.-Q., . . Rodriguez, R. A. Sanchez. (2014). Adaptation planning and implementation. In C. B. Field, V. R. Barros, D. J. Dokken, K. J. Mach, M. D. Mastrandrea, T. E. Bilir,. . L. L. White (Eds.), Climate Change 2014: Impacts, adaptation, and vulnerability. Part A: Global and sectoral aspects. Contribution of Work- 
ing Group II to the Fifth Assessment Report of the Intergovernmental Panel of Climate Change (pp. 869-898). Cambridge, UK: Cambridge University Press.

Neudorfer, N. S. (2015). Development, democracy and corruption: How poverty and lack of political rights encourage corruption. Journal of Public Policy, 35(5), 421-457.

Nurse, L. A., McLean, R. F., Agard, J., Briguglio, L. P., Duvat-Magnan, V., Pelesikoti, N., . . Webb, A. (2014). Small islands. In V. R. Barros et al. (Eds.), Climate Change 2014: Impacts, adaptation, and vulnerability: Part B: Regional aspects. Contribution of Working Group II to the Fifth Assessment Report of the Intergovernmental Panel on Climate (pp. 1613-1654). Cambridge, UK: Cambridge University Press.

Paavola, J., \& Adger, W. N. (2006). Fair adaptation to climate change. Ecological Economics, 56(4), 594-609.

Persson, A., \& Remling, E. (2014). Equity and efficiency in adaptation finance: Initial experiences of the Adaptation Fund. Climate Policy, 14(4), 488-506.

Persson, Å., Klein, R. J. T., Kehler Siebert, C., Müller, B., Hoffmeister, J., Lazarus, M., \& Takama, T. (2009). Adaptation finance under a Copenhagen agreed outcome. Retrieved from http://www.oxfordclimatepolicy.org/publications/ documents/sei_adaptation_finance_persson.pdf.

Pickering, J. (2012). Adaptation finance in the Asia-Pacific region: Strengthening fairness, effectiveness and transparency in allocation. Retrieved from https://www.research gate.net/profile/Jonathan_Pickering/publication/277159230_Adaptation_fin ance_in_the_Asia-Pacific_region_strengthening_fairness_effectiveness_and_ transparency_in_allocation/links/55641f1608ae8c0cab36fae7.pdf.

Remling, E., \& Persson, Å. (2015). Who is adaptation for? Vulnerability and adaptation benefits in proposals approved by the UNFCCC Adaptation Fund. Climate and Development, 7(1), 16-34.

Roberts, J. T., \& Parks, B. C. (2007). A climate of injustice: Global inequality, NorthSouth politics, and climate policy. Cambridge, MA.: MIT Press.

Robinson, S.-a., \& Dornan, M. (2017). International financing for climate change adaptation in Small Island Developing States. Regional Environmental Change, 17(4), 1103-1115.

Saha, S., Gounder, R., Campbell, N., \& Su, J. J. (2014). Democracy and corruption: A complex relationship. Crime, Law and Social Change, 61(3), 287-308.

Schlosberg, D. (2012). Climate justice and capabilities: A framework for adaptation policy. Ethics \& International Affairs, 26(4), 445-461.

Sen, A. (1999). Development as freedom. Oxford: Oxford University Press.

Shockley, K. (2014). Sourcing stability in a time of climate change. Environmental Values, 23(2), 199-217.

Shue, H. (1980). Basic rights: Subsistence, affluence, and U.S. foreign policy. Princeton, NJ: Princeton University Press.

Sigman, R., \& Lindberg, S. I. (2015). The index of egalitarian democracy and its components: V-Dem's conceptualization and measurement. Retrieved from https://www.v- 
dem.net/media/filer_public/61/75/6175f0f1-59fc-406d-bc07-b6ab2f88be7b /v-dem_working_paper_2015_22.pdf.

Sjöstedt, M., \& Povitkina, M. (2017). Vulnerability of Small Island Developing States to natural disasters: How much difference can effective governments make? Journal of Environment \& Development, 26(1), 82-105.

Smillie, I. (2017). Institutional corruption and Canadian foreign aid. Canadian Foreign Policy, 23(1), 47-59.

Stadelmann, M., Michaelowa, A., Butzengeiger-Geyer, S., \& Köhler, M. (2015). Universal metrics to compare the effectiveness of climate change adaptation projects. In W. Leal Filho (Ed.), Handbook of climate change adaptation (pp. 2143 2160). Berlin, Heidelberg: Springer.

Stadelmann, M., Persson, Å., Ratajczak-Juszko, I., \& Michaelowa, A. (2014). Equity and cost-effectiveness of multilateral adaptation finance: Are they friends or foes? International Environmental Agreements: Politics, Law and Economics, 14(2), $101-120$.

Thomas, A. M. (2010). What do the Worldwide Governance Indicators measure? The European Journal of Development Research, 22(1), 31-54.

Transparency International (Ed.). (2011). Global corruption report: Climate change. London and Washington, DC: Earthscan.

Transparency International. (2018). Climate adaptation finance governance standards: A new approach piloted in the Maldives and Bangladesh. Retrieved from https://www.transparency.org/whatwedo/publication/climate_adaptation_fi nance_governance_standards.

United Nations. (1948). Universal Declaration of Human Rights.

UNFCCC. (2018). UNFCCC Standing Committee on Finance: 2018 biennial assessment and overview of climate finance flows technical report. Retrieved from https://unfccc. int/topics/climate-finance/resources/biennial-assessment-of-climate-finance.

Vogl, F. (2012). Waging war on corruption, inside the movement fighting the abuse of power. Lanham: Rowman \& Littlefield.

Watson, C., Bird, N., Schalatek, L., \& Keil, K. (2017). Climate finance regional briefing: Small Island Developing States (Climate Finance Fundamentals No. 12). Washington.

World Bank. (2018). Worldwide Governance Indicators. Retrieved from http://info.worldbank.org/governance/wgi/\#reports.

Weikmans, R. (2016). Dimensions éthiques de l'allocation du financement international de l'adaptation au changement climatique. VertigO, 16(2), 1-32.

Weikmans, R., Timmons Roberts, J., Baum, J., Bustos, M. C., \& Durand, A. (2017). Assessing the credibility of how climate adaptation aid projects are categorised. Development in Practice, 27(4), 458-471.

Weiler, F., Klöck, C., \& Dornan, M. (2018). Vulnerability, good governance, or donor interests? The allocation of aid for climate change adaptation. World Development, 104, 65-77. 
Winters, M. S. (2010). Accountability, participation and foreign aid effectiveness. International Studies Review, 12, 218-243.

World Health Organization. (2019). Cost-effectiveness analysis for health interventions. Retrieved from https://www.who.int/heli/economics/costeffanal ysis/en/.

You, J.-S. (2016). Democracy, inequality and corruption: Korea, Taiwan and the Philippines compared. Cambridge, UK: Cambridge University Press.

Zellentin, A. (2015). Climate justice, Small Island Developing States \& cultural loss. Climatic Change, 133(3), 491-498. 